\section{DISCHARGE OF BILIARY CALCULI BY ULCERATION THROUGH THE ABDOMINAL PARIETES.}

To the Editor of THE LANCET.

SIR,-I brought the following case to the notice of the Halifax Medical Society, and as it is apparently a case of such rare occurrence (none of the medical gentlemen present having met with a similar one), you may probably deem it worthy of insertion in your columns.

Mr. B-, aged sixty-five, residing at King Cross, near Halifax, consulted me on August the 25th last. He complained of nausea and vomiting, great pain and tenderness over the abdomen, about the junction of the right hypochondriac and epigastric regions; in this situation there was dulness on percussion, and a visible enlargement extending down towards the umbilicus. The patient's skin, especially that of the face, was of a dusky yellow hue, giving one at first the impression that he was jaundiced, though on closer inspection no jaundice was found to exist. He attributed his symptoms to straining himself by wheeling a heavy barrow about a month previously. Has been a very temperate man, and up to his present illness has always enjoyed excellent health. For the last two years or more he has felt a painful sensation on leaning forward, as in the act of writing at a table, over a spot (to use his own expression) that he could cover with his thumb, which he indicated by placing his thumb immediately below the ribs, about three or four inches to the right of the median line.

I saw nothing more of him till September 8 th, when I was requested to visit him. On my arrival I found that an abscess had formed, and burst during the previous night ; a quantity of fetid matter had been discharged, together with some twenty or thirty gall-stones. These stones were almost colourless, friable, and soluble in ether ; they varied in size from a pin's head to a large pea (the largest weighing one drachm), the smaller ones being nearly spherical, the larger angular and more irregular in shape, appearing as if formed by the fusion of several smaller calculi. 'The opening in the abscess was situated about one inch above and a little to the right of the umbilicus; a probe could be passed about three inches into this opening. For several days two or three calculi were discharged daily. The discharge, which at first was thick and purulent, in a few days became thin and serous, but contained no bile. The patient's health rapidly improved, his appetite becoming good, the nausea and vomiting ceasing, and he no longer experienced any pain or tenderness in the abdomen.

Sept. 14th.-About a dozen more calculi were loosened and extracted by means of a probe. The swelling and in duration, which up to this time had existed above and around the umbilicus, now rapidly subsided.

19th. - Several small calculi were discharged to-day, and a large one, very triangular in shape, was with great difficulty extracted. The probe passes in now to the extent of four inches, and the discharge for the first time contains bile, the presence of which is readily ascertained by placing a few drops of the discharge and a drop or two of nitric acid on the bottom of a plate, and allowing them gradually to mix ; a green colour rapidly changing to red is produced.

After this no more calculi were discharged. The patient soon regained his accustomed health, and can lean forward without feeling any pain. The opening, which has assumed the character of a fistula, is about large enough to admit of a quill, and is still four inches deep. There is a slight discharge of pale-yellow viscid bile; sometimes two or three drachms can be collected by making firm pressure over the liver.

The absence of jaundice and the absence of bile in the discharge previous to, and its appearance immediately after, the expulsion of the last calculus (that peculiar triangular shaped one) would point to the cystic duct as the original seat of the abscess, owing to the impaction of gall-stones. If such was the case, it would tend to substantiate the statement made by many authors, that the pain caused by the passage of gall-stones is not produced until they enter the common bile duct, and that their presence in the cystic duct causes little or no pain. In this case the abdominal pain and tenderness was not in excess of what one would expect of a deep-seated abscess making its way to the sur- face; there was none of that excruciating agony which accompanies the passage of gall-stones into the bowel.

Whether the pain felt on leaning forward for two years was due to the presence of gall-stones in the cystic duct it is impossible to say; but this can be said, that it was not felt after the discharge of all the stones. I am, Sir, yours truly,

\section{Halifax.

$$
\text { Hugh Alexander Cookson, M.R.C.S. }
$$

\section{THE CURRENT INTERRUPTOR-ALTERNATOR- COMMUTATOR.}

To the Editor of THE LANCET.

SIR,-It is frequently found convenient, both in physiological and therapeutical applications, to be able to send alternately the faradaic and the galvanic current through the same rheophores. To render this possible without increasing the number of accessories, I have devised a little instrument which, as its name implies, combines with that of alternator the functions of interruptor and commutator. It can be made small enough to be fitted to the element board

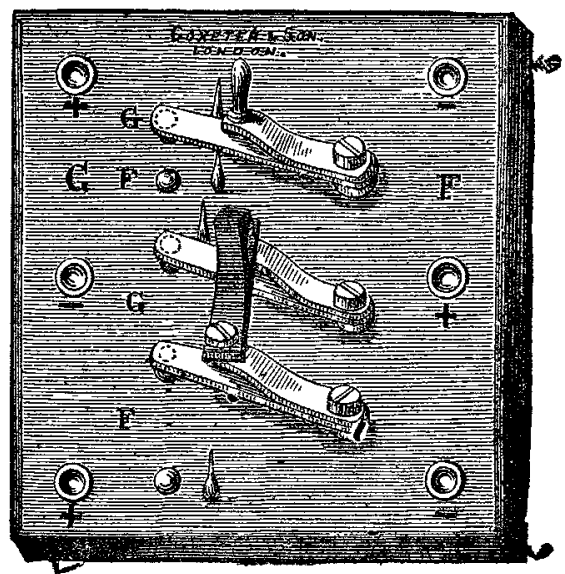

of the galvanic battery, which then possesses the chief advantage of the "combined" arrangement. The wires from the galvanic battery are fixed to $\mathrm{G}(+$ and - ) those from the faradaic to $\mathrm{F}(+$ and -$)$. The points of attachment of the rheophores are marked + and - at the bottom of the drawing. When the single index rests on $a$ (as in the illus tration), the current is reversed by moving the double index from $G$ to $F$. When again the single index is on $F$, the current passing is galvanic or faradaic when the double index points to $\mathrm{G}$ or $\mathrm{F}$ respectively. The single index also serves as interruptor by being brought to only half-way between $G$ and $F$. The signs are so arranged as to give the direct current, both faradaic and galvanic, when the instrument acts as alternator.

I am, Sir, yours \&c.,

A. DE WATTEVILle, M.A., B.Sc., M.R.C.S.,

December, 1877. Electro-therapentical Assistant to University College Hospital.

\section{THE DENTAL LICENCE.}

To the Editor of THE LANCET.

SIR,-I have been in practice as a dental surgeon for up wards of twenty-five years. I am a Member of the College of Surgeons, and, as the pupil of Mr. Edwin Saunders, I spent four years in learning the mechanical part of my profession. I therefore lay claim to having, in the most legitimate manner, obtained a knowledge of my specialty. It seems, however, that the Council of the College of Surgeons are of a different way of thinking, as, by the resolution they have lately come to in respect to the dental licence, men like myself, who declined to accept the distinguished honour of L.D.S. when it was offered to us, on the ground that the greater diploma included the less, are now to be considered as unfitted to sign the certificates of those who may in future present themselves for examination in dental surgery; whilst those who for years have been only our mechanical assistants, but who have succeeded in obtaining the dental licence, are to be permitted to do so.

Comment is unnecessary. I will not occupy your valuable 